\title{
Resveratrol inhibits hyperglycemia-driven ROS-induced invasion and migration of pancreatic cancer cells via suppression of the ERK and p38 MAPK signaling pathways
}

\author{
$\mathrm{LEICAO}^{1 *}, \mathrm{XIN} \mathrm{CHEN}^{2 *}, \mathrm{XUE} \mathrm{XIAO}^{1}, \mathrm{QINGYONG} \mathrm{MA}^{2}$ and WEI $\mathrm{LI}^{2}$ \\ ${ }^{1}$ Department of Pharmacology, School of Basic Medical Sciences, Xi'an Jiaotong University \\ Health Science Center; ${ }^{2}$ Department of Hepatobiliary Surgery, The First Affiliated \\ Hospital of Xi'an Jiaotong University, Xi'an, Shaanxi 710061, P.R. China
}

Received April 3, 2016; Accepted May 26, 2016

DOI: $10.3892 /$ ijo.2016.3559

\begin{abstract}
Increasing evidence suggests that there is a strong relationship between diabetes mellitus (DM) and pancreatic cancer. Our previous study revealed that hyperglycemia could enhance the invasive and migratory activities of pancreatic cancer cells. Resveratrol, a natural polyphenolic phytoalexin, has many biological and pharmaceutical properties, including antioxidant and anti-tumorigenic capabilities. The aim of the present study was to evaluate whether resveratrol affects hyperglycemia-induced reactive oxygen species (ROS) production as well as the invasion and migration of pancreatic cancer and its underlying mechanisms. Human pancreatic cancer Panc-1 cells were exposed to high glucose condition with or without resveratrol, N-acetylcysteine (NAC, a scavenger of free radicals), PD 98059 (an ERK inhibitor) or SB 203580 (a p38 MAPK inhibitor). The intracellular ROS and hydrogen peroxide $\left(\mathrm{H}_{2} \mathrm{O}_{2}\right)$ were determined using 2,7-dichlorodihydrofluorecein diacetate and $\mathrm{H}_{2} \mathrm{O}_{2}$ assay. MTT, wound healing assay and Transwell Matrigel invasion assay were used to detect the proliferation, migration and invasion potential of cancer cells. The expressions of uPA, E-cadherin and Glut-1 were examined using QT-PCR and western blot analysis at mRNA and protein levels. The activation of p-ERK, p-p38 and $\mathrm{p}-\mathrm{NF}-\mathrm{kB}$ were measured by western blot analysis. The results of the present study showed that resveratrol could significantly decrease high glucose-induced production of ROS and $\mathrm{H}_{2} \mathrm{O}_{2}$ in Panc-1 cells. Resveratrol was also able to inhibit high
\end{abstract}

Correspondence to: Dr Wei Li or Dr Qingyong Ma, Department of Hepatobiliary Surgery, The First Affiliated Hospital of Xi'an Jiaotong University, 277 West Yanta Road, Xi'an, Shaanxi 710061, P.R. China

E-mail: 289421999@qq.com

E-mail: 13572512207@163.com

${ }^{*}$ Contributed equally

Key words: resveratrol, hyperglycemia, reactive oxygen species, MAPK signaling pathway, invasion, pancreatic cancer glucose-induced proliferation, migration and invasion of pancreatic cancer cells. High glucose-modulated expression of uPA, E-cadherin and Glut-1 were inhibited by resveratrol. In addition, high glucose-induced activation of ERK and p38 MAPK signaling pathways as well as the transcription factor $\mathrm{NF}-\kappa \mathrm{B}$ could also be suppressed by resveratrol. Furthermore, resveratrol was able to suppress $\mathrm{H}_{2} \mathrm{O}_{2}$-induced migration and invasion abilities of pancreatic cancer cells. Taken together, these data indicate that resveratrol plays an important role in suppressing hyperglycemia-driven ROS-induced pancreatic cancer progression by inhibiting the ERK and p38 MAPK signaling pathways, providing evidence that resveratrol might be a potential candidate for chemoprevention of pancreatic cancer.

\section{Introduction}

Pancreatic cancer is a highly malignant and lethal tumor with a 5-year survival rate of less than 5\%, partially because of the lack of early diagnosis and treatment options (1). Although the incidence of most other cancers have been declining, the rate of incidence for pancreatic cancer continues to increase by $1.5 \%$ per year (1). It has been projected that pancreatic cancer will become the leading cause of cancer-related deaths in the USA by 2050 (2). In China, it has been estimated that 90,100 subjects will be newly diagnosed with pancreatic cancer and will account for 79,400 cancer-related death in 2015 (3). However, there are very limited therapeutic options for pancreatic cancer currently. Therefore, it is important to gain increased understanding of tumor risk factors to allow for early disease detection and the development of therapeutic strategies.

Epidemiologic studies as well as many meta-analyses have established clear evidence for the association between diabetes mellitus (DM) and pancreatic cancer that DM is not only a risk factor, but also a consequence of pancreatic cancer $(4,5)$. Approximately $85 \%$ of patients diagnosed with pancreatic cancer have impaired glucose tolerance or even DM (6). Our previous studies demonstrated that hyperglycemia could not only promote the proliferation of pancreatic cancer cells, but also enhance the invasive ability in pancreatic cancer (7-9). We 
proved that high glucose-induced hydrogen peroxide $\left(\mathrm{H}_{2} \mathrm{O}_{2}\right)$ production contributes to the invasion in pancreatic cancer cells by modulating the expression of the metastasis-related factor urokinase plasminogen activator (uPA) through the activation of the extracellular signal-regulated kinase (ERK) and p38 mitogen activated protein kinase (MAPK) signaling pathways (10).

Reactive oxygen species (ROS), including $\mathrm{H}_{2} \mathrm{O}_{2}$, generated by the mitochondrial respiratory chain are a number of chemically reactive molecules derived from oxygen, which play a significant role in the initiation and progression of cancer (11). ROS may play dual roles in cancer progression in a dosedependent manner. On the one hand, excess ROS production can cause oxidative damage and trigger cancer cell death; on the other hand, mild intracellular ROS can stimulate tumor progression by promoting cell proliferation, survival, invasion and metastasis (12). Our previous studies have demonstrated that both hyperglycemic condition and superoxide dismutase (SOD)-induced mild ROS production were able to promote the invasive and migratory activities of pancreatic cancer $(9,13)$. MAPK signaling pathways are important signaling cascades downstream of ROS that is involved in tumor migration and invasion (14).

Resveratrol (trans-3,4',5-trihydroxystilbene), a natural polyphenolic phytoalexin, has been found in various plants (such as grape skin and red wine) and in many types of traditional Chinese medicines (such as Rheum officinale Baill and Polygonum cuspidatum) (15). In recent years, resveratrol is gaining more and more attention for its anticancer effects and anti-oxidant properties as well as the influence on glucose metabolism $(16,17)$. Our previous study has demonstrated that resveratrol could inhibit the growth of pancreatic cancer cells by inhibiting cell proliferation and promoting cell apoptosis via inhibition of the Hh signaling pathway (18). We have also shown that resveratrol plays an important role in suppressing the proliferation and epithelial-mesenchymal transition of pancreatic cancer cells via the PI-3K/Akt/NF- $\kappa B$ signaling pathway (19). Recently, we have also proven that resveratrol could suppress hypoxia-driven ROS-induced pancreatic cancer invasive and migratory abilities by inhibiting the $\mathrm{Hh}$ signaling pathway (20). However, whether resveratrol could influence hyperglycemia-induced proliferation and migration of pancreatic cancer cells has not been elucidated.

In the present study, we tested the hypothesis that resveratrol is able to inhibit hyperglycemia-induced production of ROS and $\mathrm{H}_{2} \mathrm{O}_{2}$ as well as the invasion and migratory abilities of pancreatic cancer cells. We also investigated the effect of resveratrol on hyperglycemia-induced activation of ERK and p38 MAPK signaling pathways as well as the transcription factor, NF- $\mathrm{KB}$. Results from this study suggest that resveratrol treatment may be a novel option for therapy of pancreatic cancer via the inhibition of the ERK and p38 MAPK signaling pathways.

\section{Materials and methods}

Cell culture and reagents. The human pancreatic cancer cell line, Panc-1, was obtained from the American Type Culture Collection (ATCC; Manassas, VA, USA). The cells were cultured in Dulbecco's modified Eagle's medium (DMEM) medium containing $10 \%$ dialyzed heat-inactivated FBS, $100 \mathrm{U} / \mathrm{ml}$ penicillin, and $100 \mu \mathrm{g} / \mathrm{ml}$ streptomycin in a humidified atmosphere of $5 \% \mathrm{CO}_{2}$ at $37^{\circ} \mathrm{C}$. Exponentially growing cells in complete medium were pretreated for $1 \mathrm{~h}$ with $50 \mu \mathrm{M}$ resveratrol, followed by continual incubation in normal culturing conditions $(5.5 \mathrm{mM}$ glucose) or high glucose $(25 \mathrm{mM})$ conditions for indicated time intervals according to the purpose of the experiment. DMEM and fetal bovine serum (FBS) were from Gibco (Grand Island, NY, USA). Resveratrol (>99\% pure) was acquired from Xi'an Chongxin Natural Additive Co. (Xi'an, China). N-acetylcysteine (NAC) was purchased from Sigma. Millicell transwells for the invasion assays were obtained from Millipore (Billerica, MA, USA). Matrigel was from BD (Biosciences, Bedford, MA, USA). Primary antibodies against uPA, E-cadherin and glucose transporter type 1 (Glut-1) were procured from Santa Cruz Biotechnology (Santa Cruz, CA, USA). The anti-ERK, anti-phospho-ERK (Thr202/Tyr204), anti-p38 MAPK, anti-phospho-p38 MAPK (Thr180/Tyr182),

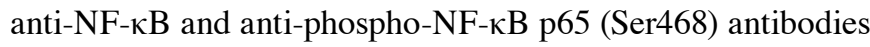
were obtained from Cell Signaling Technology (Beverly, MA, USA). The ERK inhibitor PD 98059 and the p38 MAPK inhibitor SB 203580 were obtained from Sigma Chemical Co. Nitrocellulose membranes were from Millipore. The BCA assay kit and the chemiluminescence kit were from Pierce (Rockford, IL, USA). Other reagents were purchased from common commercial sources. All drug solutions were freshly prepared on the day of testing.

MTT proliferation assays. Panc-1 cells were seeded in 96-well plates at the density of $1 \times 10^{4}$ cells/well and incubated overnight in 10\% FBS medium. The cells were then treated with resveratrol in normal glucose or high glucose condition. After incubation for 24,48 and $72 \mathrm{~h}$ at $37^{\circ} \mathrm{C}, 15 \mu \mathrm{l}$ of MTT solution [5 $\mathrm{mg} / \mathrm{ml}$ in phosphate-buffered saline (PBS)] was added to each well, and then the cells were incubated for $4 \mathrm{~h}$ at $37^{\circ} \mathrm{C}$. A total of $100 \mu l$ of DMSO was then added to each well. The optical density (OD) value at $490 \mathrm{~nm}$ was determined using a spectrophotometer (Bio-Rad Laboratories, Inc., Hercules, CA, USA).

Measurement of intracellular ROS. The level of intracellular ROS was measured using the reactive oxygen species assay kit. In brief, cells were incubated with 2,7-dichlorodihydrofluorecein diacetate (DCFDA) for $30 \mathrm{~min}$, washed in PBS 3 times, and fluorescence intensity measured using a fluorometer (Becton-Dickinson, Franklin Lakes, NJ, USA) with excitation at $488 \mathrm{~nm}$ and emission at $525 \mathrm{~nm}$.

Hydrogen peroxide assay. The level of intracellular $\mathrm{H}_{2} \mathrm{O}_{2}$ was measured using a commercial kit (hydrogen peroxide assay kit) according to the manufacturer's instructions. In this kit, ferrous ions $\left(\mathrm{Fe}^{2+}\right)$ were oxidative to ferric ions $\left(\mathrm{Fe}^{3+}\right)$ by $\mathrm{H}_{2} \mathrm{O}_{2}$. The $\mathrm{Fe}^{3+}$ then formed a complex with an indicator dye xylenol orange and produced a visible purple colored complex which could be measured with a microplate reader at a wavelength of 560-590 nm (Bio-Rad Laboratories).

Wound healing assay. Cell migratory ability was detected by a wound-healing assay. Panc-1 cells were seeded in 24-well plates $\left(1.0 \times 10^{5}\right.$ cells $\left./ 500 \mu \mathrm{l}\right)$. After the cells grew to $90-100 \%$ 
confluence, a sterile pipette tip was used to produce a wound line between the cells. Cellular debris was removed by washing with PBS and then allowed to migrate for $24 \mathrm{~h}$. Images were taken at time 0 and $24 \mathrm{~h}$ post-wounding under a Nikon Diaphot TMD inverted microscope (magnification, $\mathrm{x} 10$ ). The relative distance traveled by the leading edge from 0 to $24 \mathrm{~h}$ was assessed using Photoshop software $(n=5)$.

Transwell Matrigel invasion assay. The invasion of Panc-1 cells was performed in Millicell invasion chambers. The $8.0 \mu \mathrm{m}$ pore inserts were coated with $30 \mu \mathrm{l}$ Matrigel. After serum starvation for $24 \mathrm{~h}$, the cell suspensions $\left(5 \times 10^{4}\right)$ were added to the upper chambers in DMEM containing 1\% FBS. Simultaneously, $500 \mathrm{ml}$ of DMEM containing 20\% FBS was placed in the lower chambers. The Matrigel invasion chamber was incubated for $48 \mathrm{~h}$ in a humidified tissue culture incubator. The non-invading cells were removed from the upper surface by scraping with a wet cotton swab. After rinsing with PBS, the filter was fixed and stained with crystal violet. Invasion ability was determined by counting the stained cells.

Real-time quantitative PCR ( $Q T-P C R)$. Total RNA was extracted from the pancreatic cancer cells using the Fastgen 200 RNA isolation system (Fastgen, Shanghai, China) according to the manufacturer's protocol. Total RNA was reverse-transcribed into cDNA using the Fermentas RevertAid ${ }^{\mathrm{TM}}$ kit (MBI Fermentas, Canada). The primer sequences were as follows: uPA-F, 5'-TAAGAGCTGGTGTCTGATTG-3' and uPA-R, 5'-TTGGATGAACTAGGCTAAAA-3'; E-cadherin-F, 5'-AT TCTGATTCTGCTGCTCTTG-3' and E-cadherin-R, 5'-AGT CCTGGTCCTCTTCTCC-3'; Glut-1-F, 5'-CAACCAAGTCT AAGCCGTTGCAGTGG-3' and Glut-1-R, 5'-TGCTTGTGG ATTGAGGGTAGGA-3-3'; $\beta$-actin-F, 5'-GACTTAGTTGCG TTACACCCTTTCT-3' and $\beta$-actin-R, 5'-GAACGGTGAAG GTGACAGCAGT-3'.

The PCR reactions consisted of $30 \mathrm{sec}$ at $95^{\circ} \mathrm{C}$, followed by 40 cycles of $95^{\circ} \mathrm{C}$ for $5 \mathrm{sec}, 60^{\circ} \mathrm{C}$ for $30 \mathrm{sec}$ and $72^{\circ} \mathrm{C}$ for $30 \mathrm{sec}$. After each QT-PCR experiment, a dissociation curve analysis was conducted. The relative gene expression was calculated using the previously described $2^{-\Delta \Delta C t}$ method (21).

Western blotting. Proteins were electrophoretically resolved on a denaturing SDS-polyacrylamide gel and electrotransferred onto nitrocellulose membranes. The membranes were initially blocked with 5\% non-fat dry milk in Tris-buffered saline (TBS) for $2 \mathrm{~h}$ and then probed with antibodies against uPA, E-cadherin, Glut-1, ERK, p-ERK, p38, p-p38, NF- $\kappa$ B, $\mathrm{p}-\mathrm{NF}-\kappa \mathrm{B}$ or $\beta$-actin (loading control). After co-incubation with the primary antibodies at $4^{\circ} \mathrm{C}$ overnight, membranes were blotted with the secondary antibody for $2 \mathrm{~h}$ at $37^{\circ} \mathrm{C}$. The results were visualized using the ECL Western blotting substrate and photographed by GeneBox (SynGene).

Statistical analysis. Statistical analysis was performed using SPSS software (version 17.0; SPSS, Inc., Chicago, IL, USA). Data are presented as the means \pm SEM of three replicate assays. Differences between the groups were analyzed by analysis of variance (ANOVA). Statistical significance was set at $\mathrm{P}<0.05$. All experiments were repeated independently at least three times.

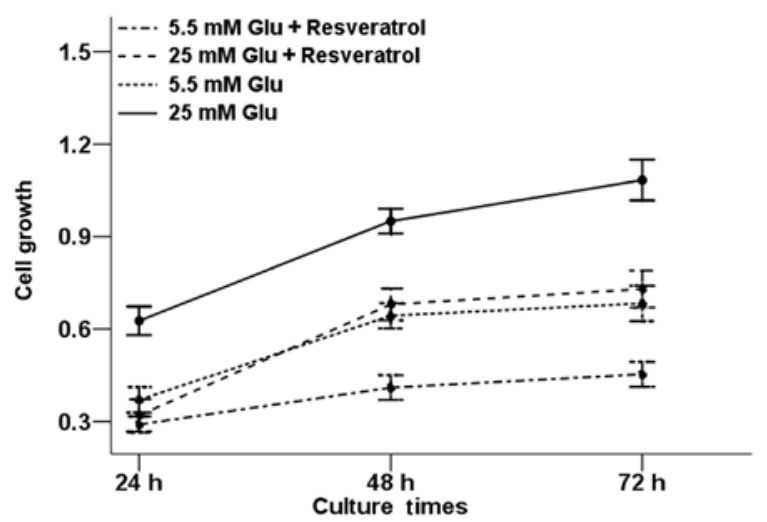

Figure 1. The effects of resveratrol on high glucose-induced pancreatic cancer proliferation. Panc-1 cells were treated with $50 \mu \mathrm{M}$ resveratrol under high glucose $(25 \mathrm{mM})$ or normal glucose $(5.5 \mathrm{mM})$ condition for 24,48 or $72 \mathrm{~h}$ to analyze the cell proliferation rates.

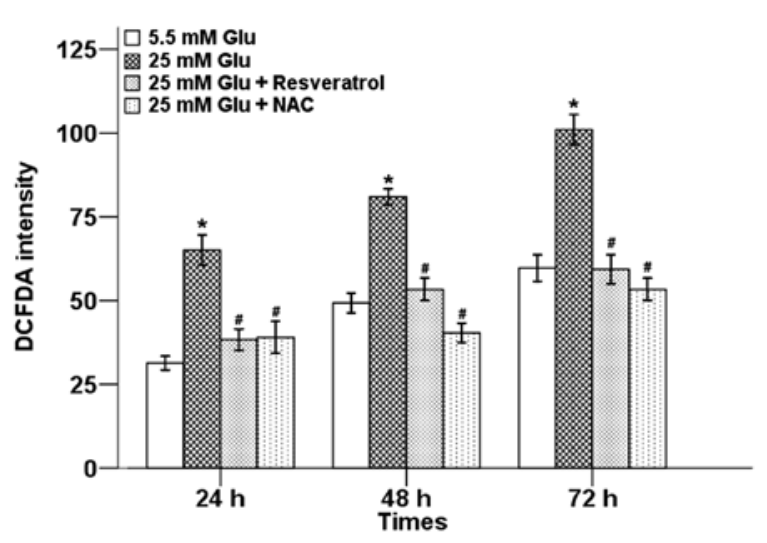

Figure 2. The effects of resveratrol on high glucose-induced ROS production Panc-1 cells were treated with $50 \mu \mathrm{M}$ resveratrol or $20 \mathrm{mM}$ NAC for 24,48 or $72 \mathrm{~h}$ for ROS detection under high glucose condition $(25 \mathrm{mM}) .{ }^{*} \mathrm{P}<0.05$ as compared with normal glucose group $(5.5 \mathrm{mM}) ;{ }^{\#} \mathrm{P}<0.05$ as compared with high glucose group ( $25 \mathrm{mM})$.

\section{Results}

Resveratrol inhibits high glucose-induced proliferation of Panc-1 cells. Our previous study proved that the $50 \%$ inhibitory concentration $\left(\mathrm{IC}_{50}\right)$ for Panc-1 cells was $\sim 50 \mu \mathrm{M}$ of resveratrol, which exhibited no cytotoxic effects on the Panc-1 cells (19). Therefore, $50 \mu \mathrm{M}$ of resveratrol was used to treat the cells for the current experiments.

In order to explore whether resveratrol could influence high glucose-induced proliferation of pancreatic cancer, Panc-1 cells were treated with high glucose condition and resveratrol alone or in combination. At the time-points indicated in Fig. 1, the proliferative rate of Panc-1 cells was determined by the MTT assay. The results showed that the proliferation of Panc-1 cells increased in high glucose condition compared with the control group and the increased rate of cell proliferation induced by high glucose was reduced in the presence of resveratrol. Resveratrol alone was also able to inhibit the proliferative ability of Panc-1 cells.

Resveratrol decreased high glucose-induced production of $\mathrm{ROS}$ and $\mathrm{H}_{2} \mathrm{O}_{2}$ in pancreatic cancer cells. To explore 


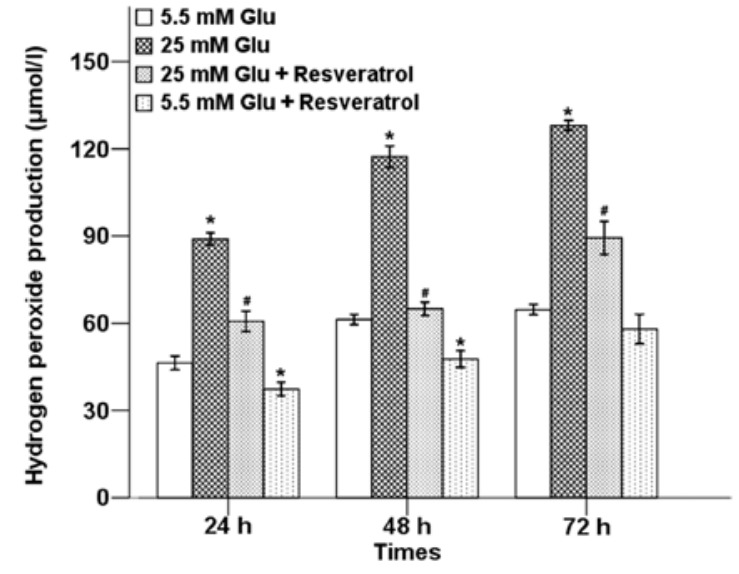

Figure 3. The effects of resveratrol on hyperglycemia-induced $\mathrm{H}_{2} \mathrm{O}_{2}$ production. Pancreatic cancer cells were treated with $50 \mu \mathrm{M}$ resveratrol for 24,48 or $72 \mathrm{~h}$ for $\mathrm{H}_{2} \mathrm{O}_{2}$ detection under high glucose condition $(25 \mathrm{mM})$. " $\mathrm{P}<0.05$ as compared with normal glucose group $(5.5 \mathrm{mM}) ;{ }^{*} \mathrm{P}<0.05$ as compared with high glucose group (25 mM). the possible relationship between resveratrol and oxidative stress, we first examined the effects of resveratrol on high glucose-induced ROS production in Panc-1 cells using the cell-permeable and redox-sensitive compound DCFDA by flow cytometry. Our results showed that high glucose significantly increased intracellular levels of ROS in a time-dependent manner, while resveratrol suppressed high glucose-induced production of ROS. NAC, a scavenger of free radicals, could also efficiently reduce the high glucose-induced ROS level in Panc-1 cells (Fig. 2).

$\mathrm{H}_{2} \mathrm{O}_{2}$ is an important component of ROS. We next examined the effects of hyperglycemia on $\mathrm{H}_{2} \mathrm{O}_{2}$ production in Panc-1 cells using $\mathrm{H}_{2} \mathrm{O}_{2}$ assay. As shown in Fig. 3, resveratrol could significantly inhibit hyperglycemia-induced production of $\mathrm{H}_{2} \mathrm{O}_{2}$ in different time-points.

Resveratrol downregulates hyperglycemia-induced activation of ERK and p38 MAPK pathways. ERK and p38 MAPK path-
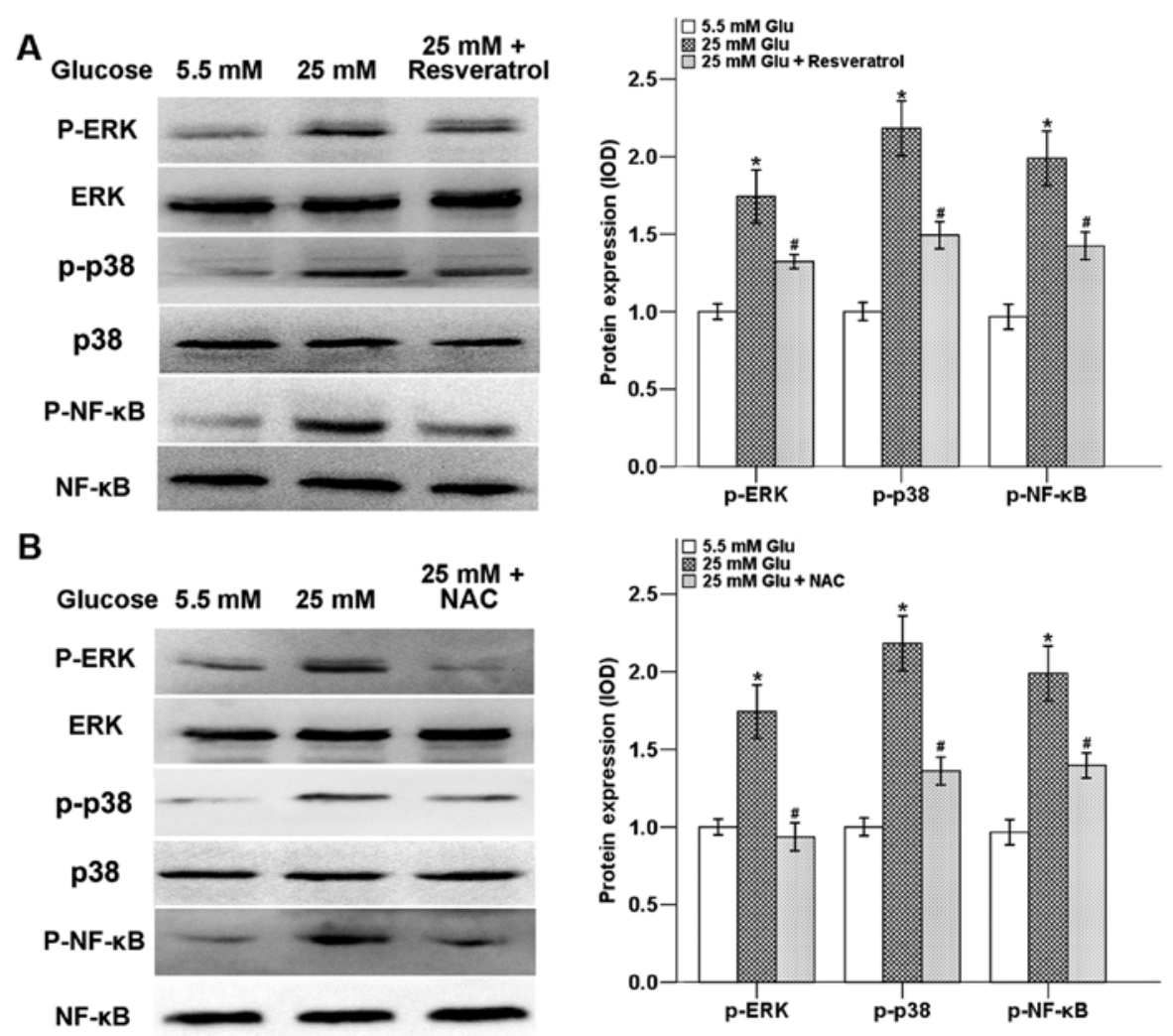

C

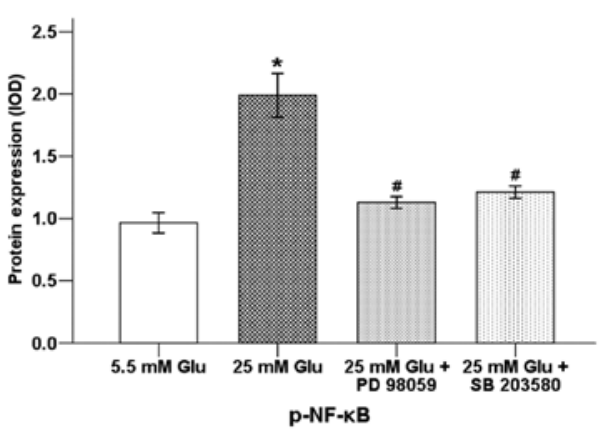

Figure 4. The roles of resveratrol in the hyperglycemia-induced phosphorylation of ERK, p38 MAPK and NF- $\mathrm{BB}$. (A) Panc-1 cells were treated with $50 \mu \mathrm{M}$ resveratrol for $24 \mathrm{~h}$ under high glucose $(25 \mathrm{mM})$ or normal glucose $(5.5 \mathrm{mM})$ condition to evaluate the phosphorylation levels of ERK, p38 MAPK and NF- $\mathrm{BB}$. (B) Panc-1 cells were treated with $20 \mathrm{mM}$ NAC and the activation of ERK, p38 MAPK and NF- $\mathrm{kB}$ were assessed via western blotting. (C) Pancreatic cancer cells were treated with PD $98059(50 \mu \mathrm{M})$ or SB $203580(20 \mu \mathrm{M})$ under high glucose condition and the activation of NF- $\mathrm{kB}$ was assessed via western blotting. ${ }^{*} \mathrm{P}<0.05$ as compared with normal glucose group $(5.5 \mathrm{mM}) ;{ }^{*} \mathrm{P}<0.05$ as compared with high glucose group $(25 \mathrm{mM})$. 

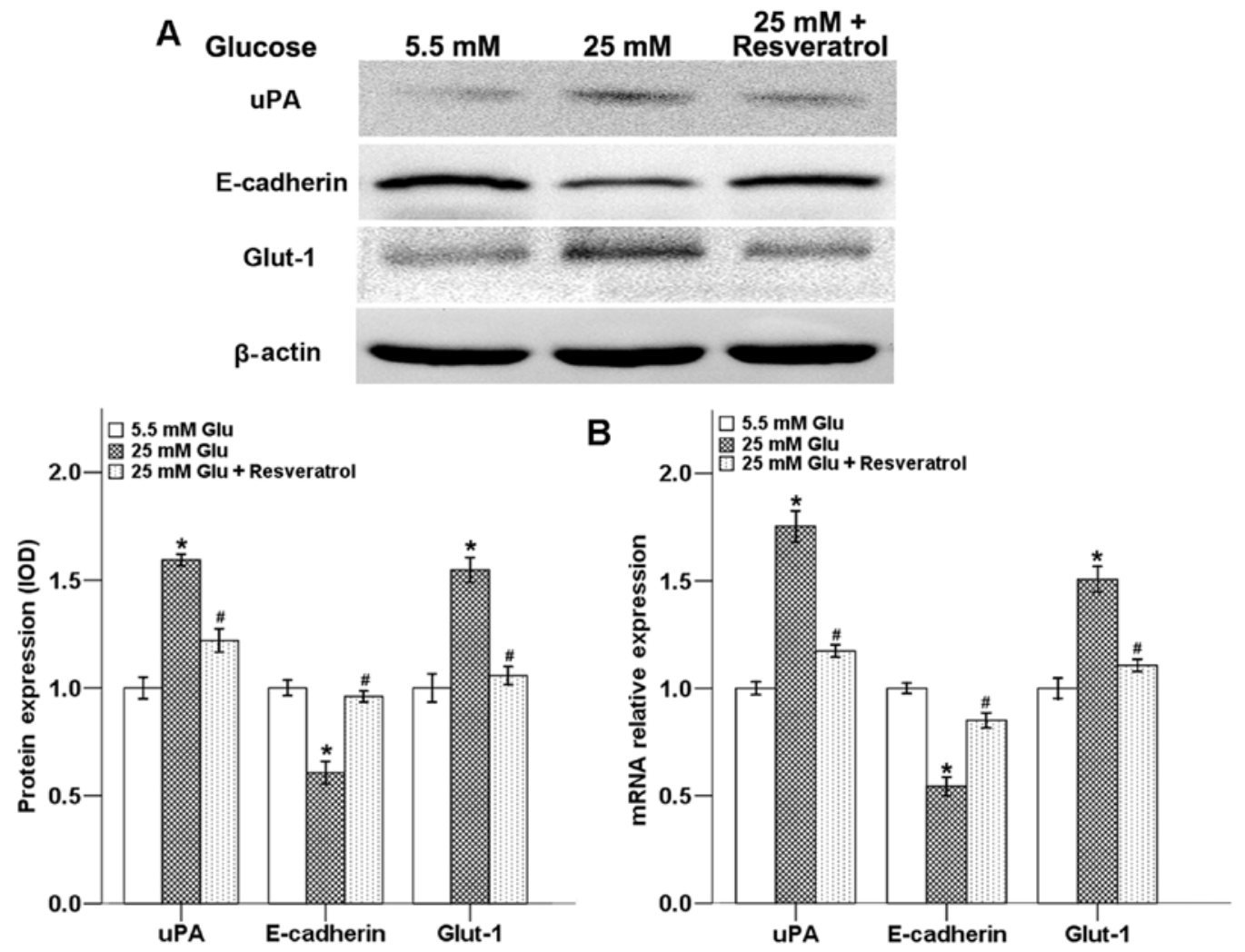

Figure 5. The effects of resveratrol on the high glucose-modulated expression of uPA, E-cadherin and Glut-1. Panc-1 cells were treated with $50 \mu \mathrm{M}$ resveratrol under high glucose $(25 \mathrm{mM})$ condition. Then, the protein (A) and mRNA (B) expression levels of uPA, E-cadherin and Glut- 1 were determined. "P<0.05 as compared with normal glucose group $(5.5 \mathrm{mM}) ;{ }^{*} \mathrm{P}<0.05$ as compared with high glucose group $(25 \mathrm{mM})$.

ways are important signaling cascades downstream of ROS, which are involved in tumor migration and invasion (14). It has been proven that ERK pathway induces activation of NF- $\kappa \mathrm{B}$ transcription factor and is associated with cell migration activity (22). Our previous study showed that high glucose activates the ERK and p38 MAPK signaling pathways as well as the transcription factors NF- $\mathrm{kB}$ and AP-1 via the production of $\mathrm{H}_{2} \mathrm{O}_{2}$ (10). In the present study, we observed that the high glucose-induced level of p-ERK and p-p38 were inhibited after a 24-h treatment of resveratrol. In addition, the high glucose-induced phosphorylation of NF- $\kappa \mathrm{B}$ was also decreased with the addition of resveratrol (Fig. 4A). In order to assess whether high glucose-induced activation of ERK and p38 MAPK signaling pathways were ROS dependent, we treated Panc-1 cells with NAC. As shown in Fig. 4B, NAC could significantly decrease high glucose-induced phosphorylation levels of ERK, p38 and NF-кB. Moreover, ERK inhibitor PD 98059 and p38 MAPK inhibitor SB203580 could inhibit the expression of $\mathrm{p}-\mathrm{NF}-\mathrm{\kappa B}$, indicating that the NF- $\kappa \mathrm{B}$ transcription factor is modulated by the ERK and p38 MAPK pathways (Fig. 4C).

Resveratrol inhibits the expression of hyperglycemiamodulated metastasis-related factors. Our previous study demonstrated that hyperglycemia could promote the invasive ability of pancreatic cancer cells through the regulation of metastatic-related factor uPA (9). Glut-1 is a member of the Glut family of facilitative glucose transporters that mediate $\mathrm{Na}^{+}$-independent cellular uptake of glucose. Glut-1 accounts for the high uptake of glucose by malignant cells (23). The results of many studies have also provided evidence that Glut-1 is intimately related with epithelial mesenchymal transition (EMT) of tumor cells and may contribute to cancer development by the activation of the ERK and NF- $\mathrm{KB}$ pathway (24-26). In the present study, we showed that high glucose condition downregulated the protein level of the E-cadherin, while the expression of uPA and Glut-1 were strongly increased. Resveratrol could significantly reverse all of these high glucose-induced effects (Fig. 5A).

To evaluate the effects of high glucose and resveratrol on the expression of E-cadherin, uPA and Glut-1 at mRNA level, we determined these factors in Panc-1 cells using QT-PCR. As shown in Fig. 5B, resveratrol reversed the high glucosemodulated metastatic-related factors at the mRNA level, and the trend was consistent with the protein results.

Resveratrol inhibits hyperglycemia-induced wound closure and cell invasion of pancreatic cancer cells. Migration and invasion are important processes that lead to the ability of cancer cells to form metastasis. A wound-healing assay was used to test the effect of resveratrol on hyperglycemiainduced pancreatic cancer cell motility. Results showed that the 24-h incubation of hyperglycemia significantly increased the migratory ability of Panc- 1 cells. Resveratrol counter-balanced this effect of hyperglycemia (Fig. 6). In addition, NAC, PD 98059 and SB 203580 could also inhibited hyperglycemia-induced wound closure of pancreatic cancer cells. 

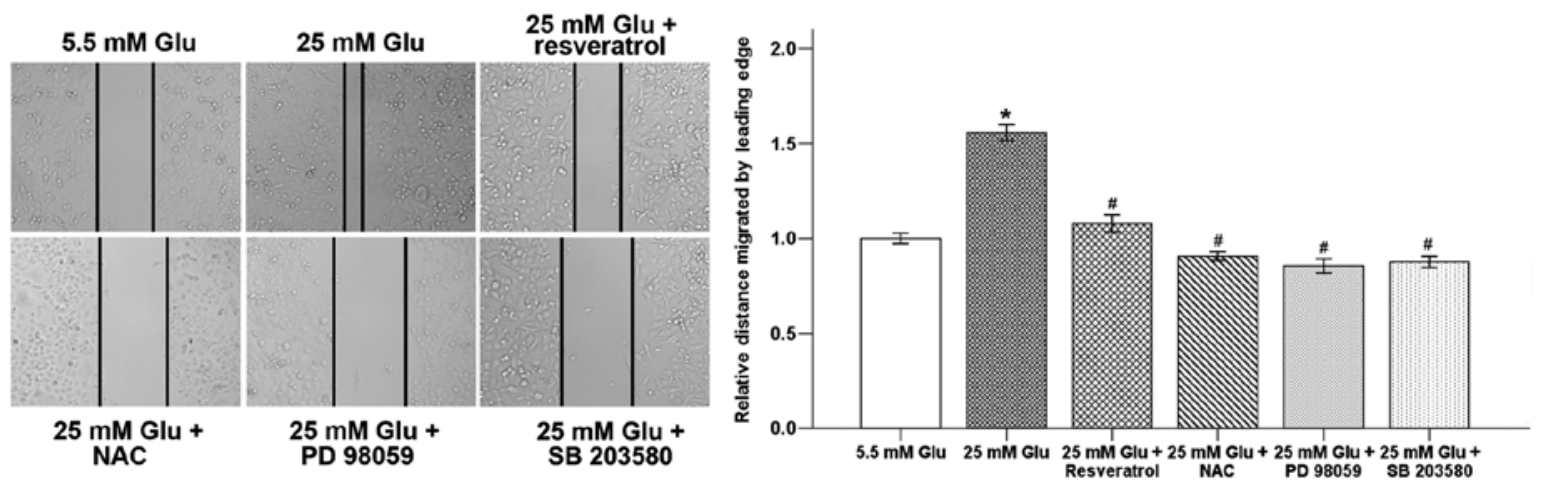

Figure 6. The effects of resveratrol on high glucose-induced migration ability of cancer cells. The confluent monolayer was wounded with a sterile pipette tip, and the cells were allowed to migrate for $24 \mathrm{~h}$. The migratory ability of Panc-1 cells was enhanced under high glucose ( $25 \mathrm{mM})$ condition, whereas the addition of resveratrol reduced the migration of pancreatic cancer cells. ${ }^{*} \mathrm{P}<0.05$ as compared with normal glucose group $(5.5 \mathrm{mM}) ;{ }^{\#} \mathrm{P}<0.05$ as compared with high glucose group $(25 \mathrm{mM})$.
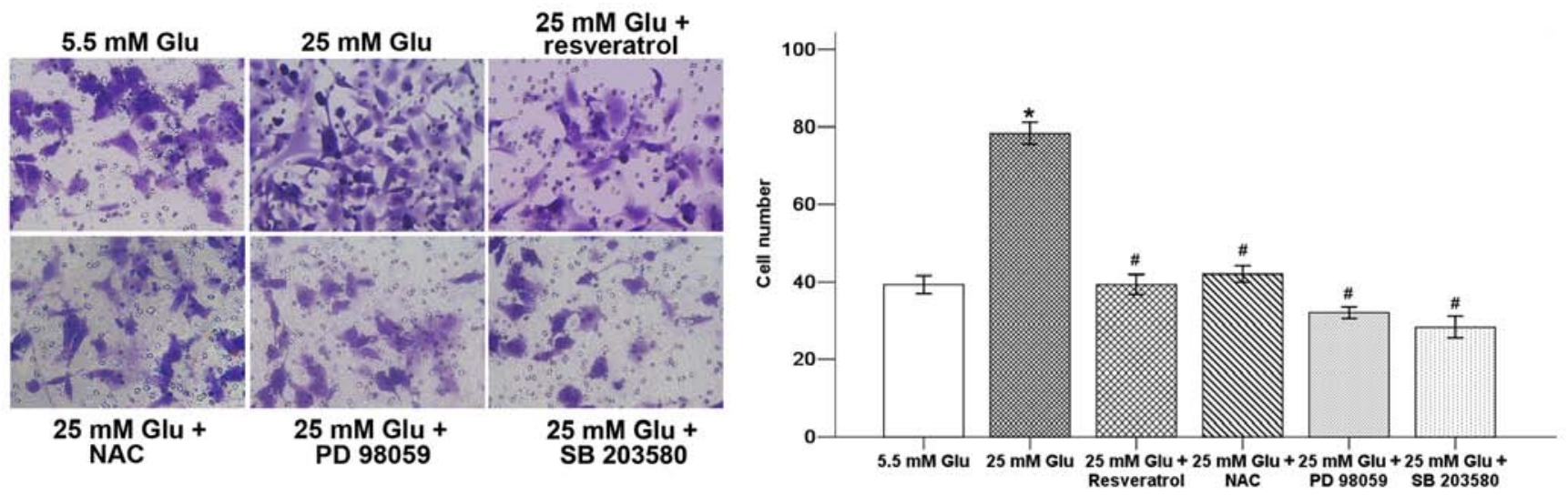

Figure 7. The effect of resveratrol on high glucose-induced invasion ability of cancer cells. Panc-1 cells were exposed to high glucose condition ( $25 \mathrm{mM})$ as well as $50 \mu \mathrm{M}$ resveratrol, $20 \mathrm{mM} \mathrm{NAC}, 50 \mu \mathrm{M}$ PD 98059 or $20 \mu \mathrm{M} \mathrm{SB} 203580$ for $48 \mathrm{~h}$, the number of migrated cells was quantified by counting the number of cells from 10 random fields at $\times 200$ magnification. ${ }^{*} \mathrm{P}<0.05$ as compared with normal glucose group $(5.5 \mathrm{mM})$; ${ }^{*} \mathrm{P}<0.05$ as compared with high glucose group $(25 \mathrm{mM})$.

A

Control
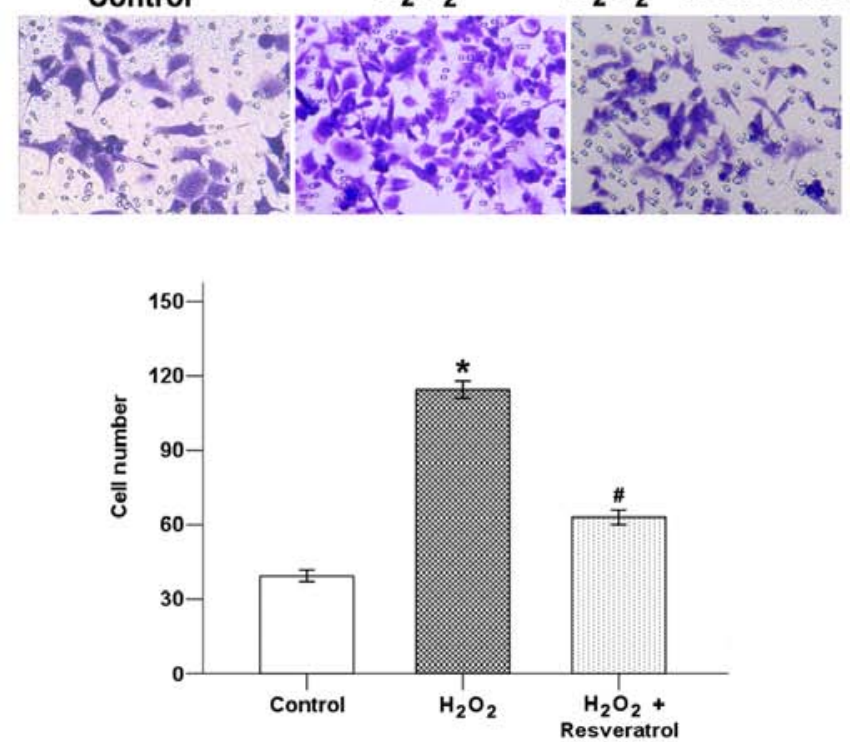

B
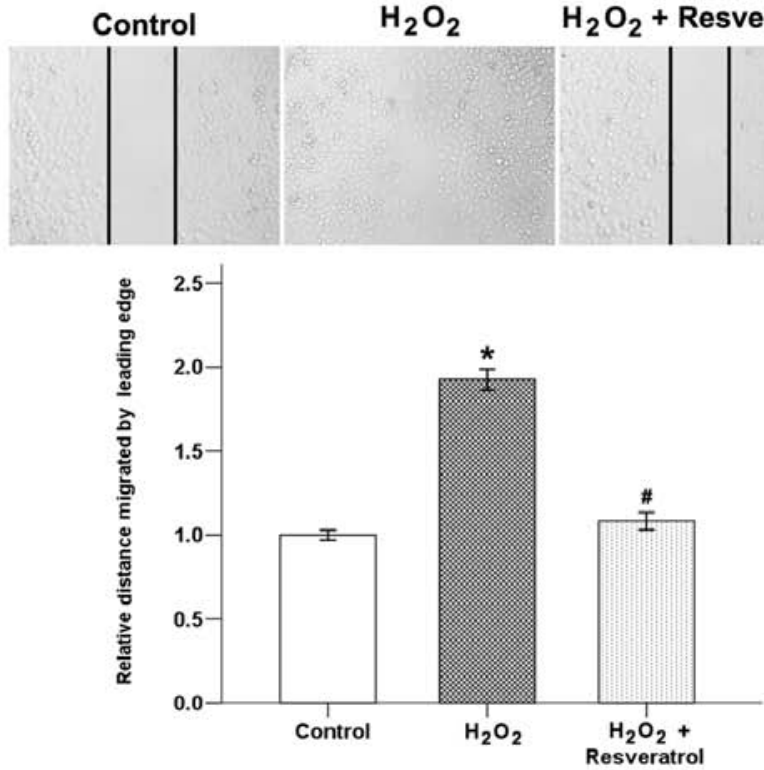

Figure 8. The effect of resveratrol on $\mathrm{H}_{2} \mathrm{O}_{2}$-induced cancer cell invasion and migration. Panc-1 cells were treated with $200 \mu \mathrm{M} \mathrm{H} \mathrm{H}_{2} \mathrm{O}_{2}$ with or without $50 \mu \mathrm{M}$ resveratrol. (A) The effects of resveratrol in pancreatic cancer cell invasion. The number of invasive cells was quantified by counting the number of cells from 10 random fields at $\mathrm{x} 200$ magnification. (B) Resveratrol significantly inhibited $\mathrm{H}_{2} \mathrm{O}_{2}$-induced migration of cells into the denuded areas. "P<0.05 as compared with control group; ${ }^{\#} \mathrm{P}<0.05$ as compared with $\mathrm{H}_{2} \mathrm{O}_{2}$ group. 
In order to confirm whether resveratrol could influence hyperglycemia-induced cancer cell invasive ability, we used a Transwell invasion assay. As shown in Fig. 7, hyperglycemia significantly increased pancreatic cancer invasion, while resveratrol decreased the average cell number that invaded into the lower chamber. NAC, PD 98059 and SB 203580 could also inhibit hyperglycemia-induced invasion of pancreatic cancer cells. These results indicate that resveratrol inhibits migration and invasion of pancreatic cancer cells under high glucose condition, which might be attributed to the ROS/ERK/NF- $\kappa \mathrm{B}$ and ROS/p38 MAPK/NF- $\mathrm{BB}$ pathways.

Resveratrol inhibits $\mathrm{H}_{2} \mathrm{O}_{2}$-induced migration and invasion of pancreatic cancer cells. To examine the potential antiinvasive effects of resveratrol on $\mathrm{H}_{2} \mathrm{O}_{2}$, the invasion ability of Panc-1 cells treated with resveratrol were analyzed. As shown in Fig. 8A, $\mathrm{H}_{2} \mathrm{O}_{2}$ exposure significantly increased the average cell number that invaded into the lower chamber. Resveratrol could efficiently reduce the $\mathrm{H}_{2} \mathrm{O}_{2}$-induced invasive ability of the cancer cells. In addition, $\mathrm{H}_{2} \mathrm{O}_{2}$ exposure for $24 \mathrm{~h}$ caused a significant increase in the migration of Panc-1 cells, whereas the cells treated with resveratrol showed delay in wound closure (Fig. 8B). These findings indicate that resveratrol might be an effective inhibitor of $\mathrm{H}_{2} \mathrm{O}_{2}$-induced migration and invasion of pancreatic cancer cells.

\section{Discussion}

As one of the most lethal malignant diseases, pancreatic cancer is characterized by poor outcome, short survival duration and resistance to therapy, due to its local recurrence, lymph node and liver metastases and peritoneal dissemination (27). Therefore, the exploration of risk factors, and metastatic mechanisms might lead to more effective therapeutic strategies for pancreatic cancer. DM, a common metabolic disorder characterized by hyperglycemia, has been postulated to be both an independent risk factor and a consequence for pancreatic cancer in recent years (28). A meta-analysis of 6 case-control studies and 3 cohort studies showed that a 2-fold higher risk of pancreatic cancer was observed in type-1 DM patients compared with individuals without DM (5). Another meta-analysis from three large case-control studies revealed a 1.8-fold increase in risk of pancreatic cancer associated with type-2 DM (7). Our previous study has also proven that high glucose may worsen the prognosis of pancreatic cancer by enhancing their migratory and invasive ability through $\mathrm{H}_{2} \mathrm{O}_{2}$ production via the activation of ERK and p38 MAPK signaling pathways $(9,10)$. In the present study, we focus on whether resveratrol is able to suppress hyperglycemia-induced cancer invasion and migration abilities and its underlying mechanism.

Our data showed that resveratrol could significantly decrease high glucose-induced production of ROS and $\mathrm{H}_{2} \mathrm{O}_{2}$ in Panc-1 cells. Resveratrol was also able to inhibit high glucose-induced proliferation, migration and invasion abilities of pancreatic cancer cells. High glucose-modulated expression of uPA, E-cadherin and Glut-1 were inhibited by resveratrol. In addition, high glucose-induced activation of ERK and p38 MAPK signaling pathways as well as the transcription factor $\mathrm{NF}-\kappa \mathrm{B}$ could also be suppressed by resveratrol. Furthermore, resveratrol suppressses $\mathrm{H}_{2} \mathrm{O}_{2}$ induced migration and invasion of pancreatic cancer cells. Our results indicate that resveratrol inhibits migration and invaison of pancreatic cancer cells under high glucose condition, which might be attributed to the ROS/ERK/NF- $\mathrm{BB}$ and ROS/p38 $\mathrm{MAPK} / \mathrm{NF}-\kappa \mathrm{B}$ pathways.

Recent studies showed that resveratrol was able to inhibit the proliferation and induce apoptosis as well as cell cycle arrest $(20,29)$, moreover, it inhibited metastasis and invasion of pancreatic cancer cells (19). In addition, resveratrol suppressed the proliferation and viability of pancreatic cancer stem cells and enhance the chemoradiosensitization of pancreatic cancer cells $(30,31)$. Resveratrol can inhibit tumor biological behavior through multiple signaling pathways. We have proven that resveratrol plays an important role in suppressing the proliferation and EMT of pancreatic cancer cells via the PI-3K/Akt/ $\mathrm{NF}-\kappa \mathrm{B}$ signaling pathway (19). Recently, we have also shown that resveratrol could suppress hypoxia-driven ROS-induced pancreatic cancer invasive and migratory abilities by inhibiting the Hh signaling pathway (20). Ji et al (32) proved that resveratrol could downregulate MALAT1 and decrease nuclear localization of $\beta$-catenin, which in turn attenuated $\mathrm{Wnt} / \beta$ catenin signaling pathway and led to the inhibition of invasion and metastasis of colorectal cancer cells. In addition, resveratrol could also inhibit hypoxia-induced HIF-1 $\alpha$ accumulation and VEGF expression in both human tongue squamous cell carcinomas and hepatoma cells via the suppression of ERK1/2 and Akt signaling pathway (33). In the present study, we found that resveratrol was able to inhibit high glucose-induced invasion and migration abilities via the suppression of the ERK and p38 MAPK signaling pathways.

Insulin resistance, hyperinsulinemia, oxidative stress and hyperglycemia are the primary characteristics of DM, but all of these factors potentially promote tumor progression in various ways (27). It has been reported that resveratrol is able to attenuate hypoxia-induced insulin resistance in rats (34). Brasnyó et al (35) showed that resveratrol could improve insulin sensitivity in humans, which might be due to a resveratrol-induced decrease in oxidative stress that leads to a more efficient insulin signalling via the Akt pathway. Lin et al (36) recenly proved that resveratrol was able to inhibit glucose-induced migration of vascular smooth muscle cells mediated by focal adhesion kinase via AKT and ERK signaling pathways. Dai et al (37) indicated that resveratrol suppressed chondrosarcoma cell invasion via AKT and p38 MAPK pathways. Here, we found that resveratrol was also able to inhibit hyperglycemia-induced invasion and migration abilities of pancreatic cancer cells. Recently, several studies have described an inhibitory effect of resveratrol on cellular glucose metabolism. Jung et al (17) showed that resveratrol could suppress cancer cell ${ }^{18} \mathrm{~F}-\mathrm{FDG}$ uptake and glycolytic metabolism in a manner that depends on the capacity of resveratrol to inhibit intracellular ROS, which downregulates HIF-1 $\alpha$ accumulation. In a human hepatoblastoma line, HepG2 cells, reduction of glucose utilization by resveratrol was associated with slowed cell cycle in the $\mathrm{S}$ phase (38). Iqbal et al (39) showed that decreased glucose uptake by resveratrol in several cancer cell lines was mediated by downregulated pyruvate kinase M2 expression through inhibition of mTOR signaling. 
The MAPK signaling pathways are important signaling cascades downstream of ROS that are involved in tumor progression (14). Members of the MAPK family include ERK, c-jun NH-2 terminal kinase (JNK) and p38 MAPK. Our previous study demonstrated that a moderate amount of $\mathrm{H}_{2} \mathrm{O}_{2}$ is able to promote pancreatic cancer invasion via the activation of the ERK and p38 MAPK signaling pathways (10). We have also proven that SOD could promote the EMT of pancreatic cancer cells via the activation of the $\mathrm{H}_{2} \mathrm{O}_{2}$ /ERK/NF- $\mathrm{KB}$ axis (13). This study determined that resveratrol could inhibit the ROS/ERK/NF- $\kappa$ B and ROS/p38 MAPK/NF- $\mathrm{BB}$ pathways which in turn attenuates cell migration and invasion.

In conclusion, the present study demonstrates that resveratrol plays an important role in suppressing hyperglycemia-induced invasion and migration of pancreatic cancer cells in vitro by inhibiting the ROS/ERK/NF- $\mathrm{BB}$ and ROS/p38 $\mathrm{MAPK} / \mathrm{NF}-\kappa \mathrm{B}$ pathways. These results suggest that resveratrol might be a potential anticancer agent for the treatment of pancreatic cancer.

\section{Acknowledgements}

The present study is supported by the National Natural Science Foundation of China (Grant serial nos. 81502840 and 81301846).

\section{References}

1. Siegel RL, Miller KD and Jemal A: Cancer statistics, 2015. CA Cancer J Clin 65: 5-29, 2015.

2. Jemal A, Bray F, Center MM, Ferlay J, Ward E and Forman D: Global cancer statistics. CA Cancer J Clin 61: 69-90, 2011.

3. Chen W, Zheng R, Baade PD, Zhang S, Zeng H, Bray F, Jemal A, Yu XQ and He J: Cancer statistics in China, 2015. CA Cancer J Clin 66: 115-132, 2016.

4. Li D, Tang H, Hassan MM, Holly EA, Bracci PM and Silverman DT: Diabetes and risk of pancreatic cancer: A pooled analysis of three large case-control studies. Cancer Causes Control 22: 189-197, 2011.

5. Stevens RJ, Roddam AW and Beral V: Pancreatic cancer in type 1 and young-onset diabetes: Systematic review and meta-analysis. Br J Cancer 96: 507-509, 2007.

6. Pannala R, Basu A, Petersen GM and Chari ST: New-onset diabetes: A potential clue to the early diagnosis of pancreatic cancer. Lancet Oncol 10: 88-95, 2009.

7. Han L, Ma Q, Li J, Liu H, Li W, Ma G, Xu Q, Zhou S and Wu E: High glucose promotes pancreatic cancer cell proliferation via the induction of EGF expression and transactivation of EGFR. PLoS One 6: e27074, 2011.

8. Li J, Ma Q, Liu H, Guo K, Li F, Li W, Han L, Wang F and Wu E: Relationship between neural alteration and perineural invasion in pancreatic cancer patients with hyperglycemia. PLoS One 6: e17385, 2011.

9. Li W, Ma Q, Li J, Guo K, Liu H, Han L and Ma G: Hyperglycemia enhances the invasive and migratory activity of pancreatic cancer cells via hydrogen peroxide. Oncol Rep 25: 1279-1287, 2011.

10. Li W, Ma Z, Ma J, Li X, Xu Q, Duan W, Chen X, Lv Y, Zhou S, Wu E, et al: Hydrogen peroxide mediates hyperglycemia-induced invasive activity via ERK and $\mathrm{p} 38$ MAPK in human pancreatic cancer. Oncotarget 6: 31119-31133, 2015.

11. Trachootham D, Alexandre J and Huang P: Targeting cancer cells by ROS-mediated mechanisms: A radical therapeutic approach? Nat Rev Drug Discov 8: 579-591, 2009.

12. Nishikawa M, Hashida M and Takakura Y: Catalase delivery for inhibiting ROS-mediated tissue injury and tumor metastasis. Adv Drug Deliv Rev 61: 319-326, 2009.

13. Li W, Cao L, Han L, Xu Q and Ma Q: Superoxide dismutase promotes the epithelial-mesenchymal transition of pancreatic cancer cells via activation of the $\mathrm{H}_{2} \mathrm{O}_{2} / E R K / N F-\kappa B$ axis. Int J Oncol 46: 2613-2620, 2015.
14. Wu WS, Wu JR and Hu CT: Signal cross talks for sustained MAPK activation and cell migration: The potential role of reactive oxygen species. Cancer Metastasis Rev 27: 303-314, 2008.

15. Chen BY, Kuo CH, Liu YC, Ye LY, Chen JH and Shieh CJ: Ultrasonic-assisted extraction of the botanical dietary supplement resveratrol and other constituents of Polygonum cuspidatum. J Nat Prod 75: 1810-1813, 2012.

16. Fulda S: Resveratrol and derivatives for the prevention and treatment of cancer. Drug Discov Today 15: 757-765, 2010.

17. Jung KH, Lee JH, Thien Quach CH, Paik JY, Oh H, Park JW, Lee EJ, Moon SH and Lee KH: Resveratrol suppresses cancer cell glucose uptake by targeting reactive oxygen speciesmediated hypoxia-inducible factor-1 $\alpha$ activation. J Nucl Med 54: 2161-2167, 2013.

18. Qin Y, Ma Z, Dang X, Li W and Ma Q: Effect of resveratrol on proliferation and apoptosis of human pancreatic cancer MIA $\mathrm{PaCa}-2$ cells may involve inhibition of the Hedgehog signaling pathway. Mol Med Rep 10: 2563-2567, 2014.

19. Li W, Ma J, Ma Q, Li B, Han L, Liu J, Xu Q, Duan W, Yu S, Wang F, et al: Resveratrol inhibits the epithelial-mesenchymal transition of pancreatic cancer cells via suppression of the PI-3K/ Akt/NF-kB pathway. Curr Med Chem 20: 4185-4194, 2013.

20. Li W, Cao L, Chen X, Lei J and Ma Q: Resveratrol inhibits hypoxia-driven ROS-induced invasive and migratory ability of pancreatic cancer cells via suppression of the Hedgehog signaling pathway. Oncol Rep 35: 1718-1726, 2016.

21. Livak KJ and Schmittgen TD: Analysis of relative gene expression data using real-time quantitative PCR and the 2(-Delta Delta C(T)) method. Methods 25: 402-408, 2001.

22. Hsieh HL, Wang HH, Wu WB, Chu PJ and Yang CM: Transforming growth factor- $\beta 1$ induces matrix metalloproteinase- 9 and cell migration in astrocytes: Roles of ROS-dependent ERK- and JNK-NF- $\mathrm{B}$ pathways. J Neuroinflammation 7: 88, 2010.

23. Ito H, Duxbury M, Zinner MJ, Ashley SW and Whang EE: Glucose transporter-1 gene expression is associated with pancreatic cancer invasiveness and MMP-2 activity. Surgery 136: 548-556, 2004.

24. Cui Y, Nadiminty N, Liu C, Lou W, Schwartz CT and Gao AC: Upregulation of glucose metabolism by NF- $\kappa \mathrm{B} 2 / \mathrm{p} 52$ mediates enzalutamide resistance in castration-resistant prostate cancer cells. Endocr Relat Cancer 21: 435-442, 2014.

25. Mori A, Moser C, Lang SA, Hackl C, Gottfried E, Kreutz M, Schlitt HJ, Geissler EK and Stoeltzing O: Up-regulation of Krüppel-like factor 5 in pancreatic cancer is promoted by interleukin-1beta signaling and hypoxia-inducible factor-1alpha. Mol Cancer Res 7: 1390-1398, 2009.

26. Zuo J, Wen J, Lei M, Wen M, Li S, Lv X, Luo Z and Wen G: Hypoxia promotes the invasion and metastasis of laryngeal cancer cells via EMT. Med Oncol 33: 15, 2016.

27. Xu Q, Zong L, Chen X, Jiang Z, Nan L, Li J, Duan W, Lei J, Zhang L, Ma J, et al: Resveratrol in the treatment of pancreatic cancer. Ann NY Acad Sci 1348: 10-19, 2015.

28. Li J, Cao G, Ma Q, Liu H, Li W and Han L: The bidirectional interation between pancreatic cancer and diabetes. World J Surg Oncol 10: 171, 2012.

29. Mo W, Xu X, Xu L, Wang F, Ke A, Wang X and Guo C: Resveratrol inhibits proliferation and induces apoptosis through the hedgehog signaling pathway in pancreatic cancer cell. Pancreatology 11: 601-609, 2011.

30. Fulda S and Debatin KM: Sensitization for anticancer druginduced apoptosis by the chemopreventive agent resveratrol. Oncogene 23: 6702-6711, 2004.

31. Shankar S, Nall D, Tang SN, Meeker D, Passarini J, Sharma J and Srivastava RK: Resveratrol inhibits pancreatic cancer stem cell characteristics in human and KrasG12D transgenic mice by inhibiting pluripotency maintaining factors and epithelialmesenchymal transition. PLoS One 6: e16530, 2011.

32. Ji Q, Liu X, Fu X, Zhang L, Sui H, Zhou L, Sun J, Cai J, Qin J, Ren J, et al: Resveratrol inhibits invasion and metastasis of colorectal cancer cells via MALAT1 mediated Wnt/ $\beta$-catenin signal pathway. PLoS One 8: e78700, 2013.

33. Zhang Q, Tang X, Lu QY, Zhang ZF, Brown J and Le AD: Resveratrol inhibits hypoxia-induced accumulation of hypoxiainducible factor-1alpha and VEGF expression in human tongue squamous cell carcinoma and hepatoma cells. Mol Cancer Ther 4: 1465-1474, 2005. 
34. Carreras A, Zhang SX, Almendros I, Wang Y, Peris E, Qiao Z and Gozal D: Resveratrol attenuates intermittent hypoxia-induced macrophage migration to visceral white adipose tissue and insulin resistance in male mice. Endocrinology 156: 437-443, 2015.

35. Brasnyó P, Molnár GA, Mohás M, Markó L, Laczy B, Cseh J, Mikolás E, Szijártó IA, Mérei A, Halmai R, et al: Resveratrol improves insulin sensitivity, reduces oxidative stress and activates the Akt pathway in type 2 diabetic patients. Br J Nutr 106: 383-389, 2011.

36. Lin YC, Chen LH, Varadharajan T, Tsai MJ, Chia YC, Yuan TC, Sung PJ and Weng CF: Resveratrol inhibits glucose-induced migration of vascular smooth muscle cells mediated by focal adhesion kinase. Mol Nutr Food Res 58: 1389-1401, 2014.
37. Dai Z, Lei P, Xie J and Hu Y: Antitumor effect of resveratrol on chondrosarcoma cells via phosphoinositide 3-kinase/AKT and p38 mitogen-activated protein kinase pathways. Mol Med Rep 12: 3151-3155, 2015.

38. Massimi M, Tomassini A, Sciubba F, Sobolev AP, Devirgiliis LC and Miccheli A: Effects of resveratrol on HepG2 cells as revealed by ${ }^{1} \mathrm{H}-\mathrm{NMR}$ based metabolic profiling. Biochim Biophys Acta 1820: 1-8, 2012

39. Iqbal MA and Bamezai RN: Resveratrol inhibits cancer cell metabolism by down regulating pyruvate kinase M2 via inhibition of mammalian target of rapamycin. PLoS One 7: e36764, 2012. 